\title{
Coronatine Inhibits Stomatal Closure through Guard Cell-Specific Inhibition of NADPH Oxidase-Dependent ROS Production
}

\author{
Laila Toum ${ }^{1}$, Pablo S. Torres ${ }^{1}$, Susana M. Gallego², María P. Benavídes², \\ Adrián A. Vojnov ${ }^{1}$ and Gustavo E. Gudesblat ${ }^{1,3 *}$ \\ 1 Instituto de Ciencia y Tecnología Dr. César Milstein, Fundación Pablo Cassará, Consejo Nacional de Investigaciones \\ Cientificas y Técnicas, Buenos Aires, Argentina, ${ }^{2}$ Departamento de Química Biológica, Facultad de Farmacia y Bioquímica, \\ Universidad de Buenos Aires, Buenos Aires, Argentina, ${ }^{3}$ Instituto de Biodiversidad y Biología Experimental y Aplicada, \\ Departamento de Biodiversidad y Biología Experimental, Consejo Nacional de Investigaciones Científicas y Técnicas, \\ Facultad de Ciencias Exactas y Naturales, Universidad de Buenos Aires, Buenos Aires, Argentina
}

OPEN ACCESS

Edited by:

Abdul Latif Khan,

University of Nizwa, Oman

Reviewed by:

Prashant Singh,

Lancaster University, UK

Zonghua Wang,

Fujian Agriculture and Forestry

University, China

*Correspondence:

Gustavo E. Gudesblat ggudesblat@bg.fcen.uba.ar

Specialty section:

This article was submitted to

Plant Biotic Interactions,

a section of the journal

Frontiers in Plant Science

Received: 11 July 2016 Accepted: 23 November 2016 Published: 14 December 2016

Citation:

Toum L, Torres PS, Gallego SM,

Benavídes MP, Vojnov AA and Gudesblat GE (2016) Coronatine Inhibits Stomatal Closure through

Guard Cell-Specific Inhibition of NADPH Oxidase-Dependent ROS Production. Front. Plant Sci. 7:1851. doi: 10.3389/fpls.2016.01851
Microbes trigger stomatal closure through microbe-associated molecular patterns (MAMPs). The bacterial pathogen Pseudomonas syringae pv. tomato (Pst) synthesizes the polyketide toxin coronatine, which inhibits stomatal closure by MAMPs and by the hormone abscisic acid (ABA). The mechanism by which coronatine, a jasmonic acidisoleucine analog, achieves this effect is not completely clear. Reactive oxygen species (ROS) are essential second messengers in stomatal immunity, therefore we investigated the possible effect of coronatine on their production. We found that coronatine inhibits NADPH oxidase-dependent ROS production induced by ABA, and by the flagellin-derived peptide flg22. This toxin also inhibited NADPH oxidase-dependent stomatal closure induced by darkness, however, it failed to prevent stomatal closure by exogenously applied $\mathrm{H}_{2} \mathrm{O}_{2}$ or by salicylic acid, which induces $\mathrm{ROS}$ production through peroxidases. Contrary to what was observed on stomata, coronatine did not affect the oxidative burst induced by flg22 in leaf disks. Additionally, we observed that in NADPH oxidase mutants atrbohd and atrbohd/f, as well as in guard cell ABA responsive but flg22 insensitive mutants mpk3, mpk6, npr1-3, and lecrk-VI.2-1, the inhibition of ABA stomatal responses by both coronatine and the NADPH oxidase inhibitor diphenylene iodonium was markedly reduced. Interestingly, coronatine still impaired ABA-induced ROS synthesis in mpk3, mpk6, npr1-3, and lecrk-VI.2-1, suggesting a possible feedback regulation of $\mathrm{ROS}$ on other guard cell $\mathrm{ABA}$ signaling elements in these mutants. Altogether our results show that inhibition of NADPH oxidase-dependent ROS synthesis in guard cells plays an important role during endophytic colonization by Pst through stomata.

Keywords: Arabidopsis thaliana, coronatine, NADPH oxidase, reactive oxygen species, stomata, abscisic acid

\section{INTRODUCTION}

Stomatal pores allow plants to exchange gases with the atmosphere but can also be used by phytopathogens to colonize leaves. As a result, plants have evolved the capacity to close stomata not only in response to hormones such as abscisic acid (ABA) and abiotic stresses, but also to microbe-associated molecular patterns (MAMPs), including bacterial flagellin, elongation factor 
$\mathrm{Tu}$, lipopolysaccharide, fungal chitin, and yeast elicitor. Microbes in turn have evolved strategies to avoid closing stomata so as to colonize hosts via these openings (Arnaud and Hwang, 2014; McLachlan et al., 2014).

Stomatal closure in response to different stimuli is brought about by loss of turgor of guard cells, which is caused by the extrusion of solutes through different ion channels. These channels are regulated by a complex signaling network involving production of reactive oxygen species (ROS), nitric oxide, phospholipids, cytosolic calcium elevations, cytosolic alkalinization, and other signaling components (Kim et al., 2010; Joshi-Saha et al., 2011; Kollist et al., 2014). A minimal signaling cascade has been established for ABA-induced stomatal closure in the model plant Arabidopsis thaliana. ABA is perceived by receptors PYR/PYL/RCAR, which inhibit PP2Cs phosphatases, $\mathrm{ABI} 1$ and $\mathrm{ABI} 2$. In the absence of $\mathrm{ABA}$ these phosphatases act as inhibitors of the protein kinase OST1/SnRK2.6. Therefore ABA perception causes activation of this kinase, which phosphorylates and activates the anion channel SLAC1, an event that contributes to membrane depolarization and subsequent solute exit from guard cells (Cutler et al., 2010; Joshi-Saha et al., 2011). However, several other signaling components like those mentioned above have also been shown to be involved ABA-induced stomatal closure, indicating that signaling of this hormone likely occurs through a more complex signaling network.

The flagellin derived peptide flg22 is perceived by the RLK receptor complex FLS2-BAK1 and phosphorylates the kinase BIK1, which in turn activates by phosphorylation the NADPH oxidase AtRBOHD (Kadota et al., 2014; Li et al., 2014). This leads to ROS production, which in guard cells leads to activation of plasma membrane $\mathrm{Ca}^{2+}$ channels (Kwak et al., 2003; Thor and Peiter, 2014) and subsequently of SLAC1 anionic channel (Guzel Deger et al., 2015), causing stomatal closure. While atrbohd mutant is completely insensitive to flg22 or bacteria for stomatal closure, in the case of ABA, a double mutation in AtRBOHD and AtRBOHF leads only to a partial inhibition of stomatal closure triggered by this hormone, something likely due to the redundancy of the complex ABA signaling network (Kwak et al., 2003). NADPH oxidases are also involved in stomatal closure triggered by darkness (Desikan et al., 2004). Like AtRBOHD, mitogen activated kinases MPK3 and MPK6, which are activated by flg22 in mesophyll protoplasts, are required for stomatal closure triggered by bacterial MAMPs but not by ABA (Gudesblat et al., 2009; Montillet et al., 2013). Similarly, the MAMP-activated L-type lectin receptor kinase-VI.2 (LECRK-VI.2) is also required for stomatal closure triggered by bacterial MAMPs but not by ABA (Singh et al., 2013). Stomatal closure by certain MAMPs such as chitin and yeast elicitor, and also by the hormone salicylic acid (SA), involved in response against pathogens, requires ROS production by cell wall peroxidases. Therefore the action of these compounds is not affected in NADPH oxidase mutants, but it is by the peroxidase inhibitor salicylhydroxamic acid (SHAM; Khokon et al., 2010a,b, 2011). Functional SA signaling, involving the transcription factor NPR1, is required for stomatal closure induced by flg 22 or bacteria but not by ABA (Zeng and $\mathrm{He}$, 2010).
Several pathogens that penetrate leaves through stomata have evolved the capacity to produce compounds that prevent their closure. The bacterial pathogen Pst DC 3000 synthesizes coronatine, a polyketide toxin that mimics the active form of jasmonic acid (JA), a hormone involved in defense, jasmonoylL-isoleucine (JA-Ile; Yan et al., 2009; Geng et al., 2014), and which can reopen stomata after initial closure triggered by bacterial MAMPs, ABA, or darkness (Mino et al., 1987; Melotto et al., 2006; Egoshi et al., 2016; Panchal et al., 2016). The inhibitory effect of coronatine on stomata depends in A. thaliana on the presence of the JA receptor COI1 and the JA responsive transcription factors MYC2, ANAC019, ANAC055, and ANAC072 (Melotto et al., 2006; Zheng et al., 2012) and in tomato on the JA responsive transcription factor JA2L (Du et al., 2014). Thus, in order to inhibit stomatal closure coronatine requires the same signaling pathway as JA.

In order to gain knowledge into the mechanism of action of coronatine on stomata, in this work we investigated its effect on ROS production because these molecules act as important signaling hubs in guard cells. We found that this toxin inhibits ROS production mediated by NADPH oxidases but not by peroxidases, and does it specifically in stomata. Additionally, we observed that in atrbohd, atrbohd/f, mpk3, mpk6, npr1-3, and lecrk-VI.2-1 mutants, all affected in response to MAMPs but not to $\mathrm{ABA}$, coronatine is unable to inhibit the effect of $\mathrm{ABA}$ on stomata, even when it can still inhibit ABA-induced ROS synthesis.

\section{MATERIALS AND METHODS}

\section{Plant Material and Growth Conditions}

Plants were grown in petri dishes containing half-strength Murashige and Skoog (MS) medium with $1 \%$ sucrose under a $12 \mathrm{~h}: 12 \mathrm{~h}$ light/dark cycle (photon flux density of $90 \mu \mathrm{E}$ ) at $22-23^{\circ} \mathrm{C}$. After a week plants were transferred to a mixture of vermiculite, peat moss and perlite (1:1:1). A. thaliana L. Heynh. ecotypes Columbia-0 (Col-0) or Landsberg erecta (Ler) were used as controls. The following A. thaliana mutants were used: atrbohd, atrbohd/atrbohf (atrbohd/f; Cao et al., 1997; Torres et al., 2002), npr1-3 (Cao et al., 1997), mpk3 (SALK_151594), mpk6 (SALK_127507; Alonso et al., 2003), coi 1-16 (Ellis and Turner, 2002), ost1-2 (Mustilli et al., 2002), bik1 (Veronese et al., 2006), lecrk-VI.2-1 (SALK_070801; Singh et al., 2012), and pp2ca-1 (Kuhn et al., 2006).

\section{Chemicals}

Abscisic acid (mixed isomers), 2',7'-dichlorodihydrofluorescein diacetate ( $\left.\mathrm{H}_{2} \mathrm{DCFDA}\right), \mathrm{SHAM}, \mathrm{SA}$, diphenylene iodonium (DPI), horseradish peroxidase, luminol, and coronatine were purchased from Sigma (USA), $\mathrm{H}_{2} \mathrm{O}_{2}$ from JT Baker (USA), while flg22 was synthesized by GL Biochem (China). ABA and SHAM were dissolved in ethanol, $\mathrm{H}_{2}$ DCFDA in dimethyl sulfoxide and coronatine in methanol, keeping in all cases the final solvent concentration in assays below $1 \%$. 


\section{Stomatal Aperture Bioassays}

Stomatal bioassays were performed as previously described (Gudesblat et al., 2009). Epidermal peels from leaves of 4-weekold plants were floated in 10:10 buffer under light $(10 \mathrm{mM}$ $\mathrm{KCl}$ and $10 \mathrm{mM}$ MES-KOH, $\mathrm{pH} 6.15$ ) for $2.5 \mathrm{~h}$, then ABA (at the indicated concentrations), SA $(10 \mu \mathrm{M})$, flg22 $(5 \mu \mathrm{M})$, DPI $(20 \mu \mathrm{M})$, SHAM $(2 \mathrm{mM})$, or Pst DC3118 $\left(10^{8} \mathrm{cfu} / \mathrm{mL}\right)$ were added to the medium and peels were incubated for a further $1.5 \mathrm{~h}$. Coronatine $(1.56 \mu \mathrm{M})$ was added $10 \mathrm{~min}$ previous to other treatments. For darkness-induced stomatal experiments, after initial opening epidermal peels were incubated in buffer $10 / 10$ for $2 \mathrm{~h}$ in the dark in the presence or absence of chemicals. Promotion of closure by $\mathrm{H}_{2} \mathrm{O}_{2}$ was performed as previously described (Pei et al., 2000). The initial incubation to open stomata was performed in the presence of $0.1 \mathrm{mM} \mathrm{EGTA}$, and then $\mathrm{H}_{2} \mathrm{O}_{2}$ was added $(100 \mu \mathrm{M})$ together with $\mathrm{CaCl}_{2}(0.2 \mathrm{mM})$. Coronatine was added $10 \mathrm{~min}$ prior to the addition of other chemicals. For the inhibition of stomatal opening experiment, epidermal peels were floated in the dark in 10:0 buffer (10 mM MES-KOH pH 6.15) for $2 \mathrm{~h}$ to promote closure. Then epidermal peels were transferred to 10:10 buffer containing chemicals as described above, and were incubated in the light for an additional $2 \mathrm{~h}$ period. The aperture of 40 stomata was measured for each treatment. Data are presented as the average from 80 to 120 aperture measurements, collected from two to three independent experiments. Mock treatments were performed with 10:10 buffer.

\section{ROS Measurements}

Hydrogen peroxide production in guard cells was measured using $\mathrm{H}_{2}$ DCFDA (Murata et al., 2001). After a $2.5 \mathrm{~h}$ incubation in 10:10 buffer under light conditions, epidermal peels were transferred to a $10 \mathrm{mM}$ Tris- $\mathrm{HCl}$ pH 7.2 buffer containing $\mathrm{H}_{2}$ DCFDA $(10 \mu \mathrm{M})$ for $15 \mathrm{~min}$. Excess $\mathrm{H}_{2}$ DCFDA was removed by washing three times with $10 \mathrm{mM}$ Tris- $\mathrm{HCl} \mathrm{pH} \mathrm{7.2.} \mathrm{Then} \mathrm{peels} \mathrm{were} \mathrm{transferred}$ to $10: 10$ buffer containing $5 \mu \mathrm{M}$ flg22 or $20 \mu \mathrm{M} \mathrm{ABA}$ and incubated for $20 \mathrm{~min}$ in the dark. Coronatine $(1.56 \mu \mathrm{M})$ was added 10 min previous to flg22 and ABA. Fluorescence was observed with a Nikon Eclipse E600 fluorescence microscope (excitation 460-480 nm, emission 495-540 nm). The guard cells fluorescence was analyzed using ImageJ 1.46 software. Data is presented as the average from 80 fluorescence measurements per treatment, collected from two independent experiments. Oxidative burst measurement in leaf disks was performed using the peroxidase luminol enhanced chemiluminescence method (Gimenez-Ibanez et al., 2009). ROS production was induced in 12 leaf disks per treatment from 4- to 5-week-old plants. Disks $\left(0.25 \mathrm{~cm}^{2}\right)$ were incubated overnight in water, which was replaced by $100 \mu \mathrm{l}$ of $10 \mathrm{mM}$ Tris/ $\mathrm{HCl} \mathrm{pH} 9.5$ containing $10 \mu \mathrm{g} / \mathrm{ml}$ horseradish peroxidase and $20 \mu \mathrm{M}$ luminol. ROS were elicited with flg22 $(1 \mu \mathrm{M})$, and coronatine $(1.56 \mu \mathrm{M})$ was added simultaneously with flg22 where indicated. The measurement of chemiluminescence was performed in a plate reader PHERAstar Plus HTS, BGM Labtech. Results are presented as the average from 36 fluorescence measurements per treatment, collected from three independent experiments. The superoxide anion scavenging activity of coronatine was determined by inhibition of adrenochrome formation rate at $480 \mathrm{~nm}$ as previously described (Misra and Fridovich, 1972). The reaction mixture contained $1 \mathrm{mM}$ epinephrine $(20 \mathrm{mM}$ in $0.1 \mathrm{M} \mathrm{HCl}), 50 \mathrm{mM}$ sodium carbonate buffer $(\mathrm{pH}$ 10.2) and different concentrations of coronatine. The increase in absorbance due to the formation of the adrenochrome was followed for $10 \mathrm{~min}$ and the activity was calculated from the linear part of the curve in absence or presence of coronatine. Ascorbic acid was used as positive control of superoxide scavenging activity. Absorbance was determined in a FlexStation 3 Multi-Mode Microplate Reader (Molecular Devices). Mock treatments were performed with the respective incubation buffer.

\section{Statistical Analysis}

For statistical analysis, one-way ANOVA (post hoc Tukey's test) or two-way ANOVA (Bonferroni's method) tests were used. Statistical significances were determined with InfoStat software (InfoStat 2013 version).

\section{RESULTS}

\section{Effect of Coronatine on ROS Production in Guard Cells}

It was previously reported that coronatine can reduce stomatal closure triggered by ABA and flg22 (Melotto et al., 2006). Measurement of ROS in A. thaliana guard cells revealed that coronatine strongly inhibited their synthesis in response to both compounds, which is mediated by NADPH oxidases. By contrast, the toxin failed to inhibit stomatal closure or ROS production induced by SA, which induces the synthesis of these second messengers through peroxidases (Figures 1A,B). ROS induction by SA was higher than that elicited by flg22 or ABA, however, that did not translate into stronger stomatal closure, suggesting that ROS signaling is saturated beyond a certain concentration of ROS. These results indicate that coronatine interferes with stomatal closure through inhibition of ROS production by $\mathrm{NADPH}$ oxidases but not by peroxidases. Consistent with previous reports showing that ROS induction by SA is mediated by peroxidases, the peroxidase inhibitor SHAM inhibited closure by SA but not by flg22, while SA was capable of closing stomata in the atrbohd mutant (Supplementary Figure S1). As flg22 induces NADPH-dependent ROS production in leaf disks, we tested whether coronatine can affect it and, we found that this is not the case (Figure 2), showing that the effect of this toxin on ROS production in stomata does not occur in other leaf tissues.

\section{The Inhibitory Effect of Coronatine on Stomata Requires NADPH Oxidases}

$\mathrm{NADPH}$ oxidases enzymes generate superoxide anions as a product of NADPH oxidation, which are subsequently converted into $\mathrm{H}_{2} \mathrm{O}_{2}$ by superoxide dismutases (Bolwell, 1999). As coronatine inhibits NADPH-dependent ROS production, we considered the possibility that the toxin inhibits superoxide dismutase activity. To test it, we performed an epinephrine autoxidation assay, which generates superoxide anion that can 
A

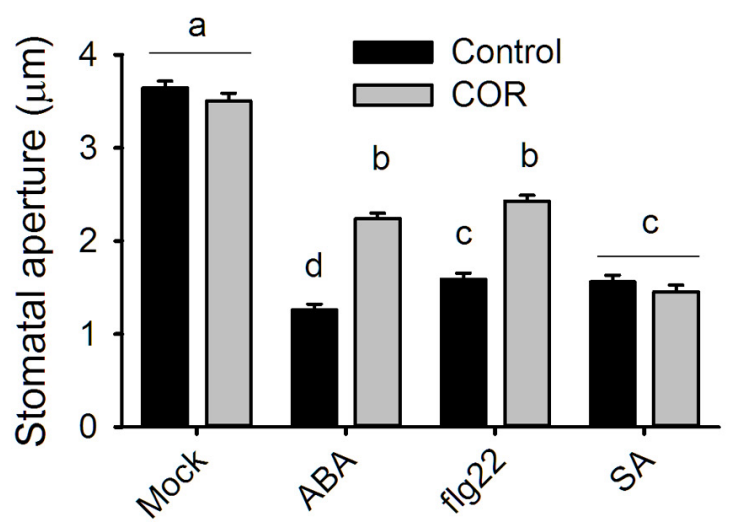

B

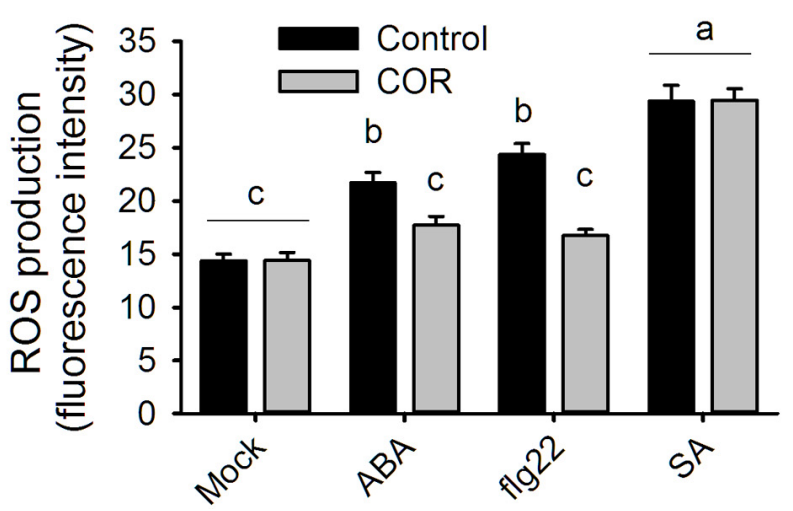

FIGURE 1 | Coronatine affects stomatal closure and ROS production by ABA and flg22 but not by SA. (A) Coronatine (COR, $1.56 \mu$ M) inhibited stomatal closure in response to $\mathrm{ABA}(20 \mu \mathrm{M})$ or flg22 $(5 \mu \mathrm{M})$ but not to $\mathrm{SA}(10 \mu \mathrm{M})$. Stomatal apertures were measured $1.5 \mathrm{~h}$ after application of the respective treatments. (B) Coronatine (COR, $1.56 \mu \mathrm{M})$ inhibited guard cell ROS production in response to ABA (20 $\mu \mathrm{M})$ or flg22 (5 $\mu \mathrm{M})$ but not to SA (10 $\mu \mathrm{M})$. ROS were detected as $\mathrm{H}_{2}$ DCFDA fluorescence in guard cells 20 min after treatment. In both experiments coronatine was added 10 min before other treatments. Different letters indicate significant differences at $p<0.05$ in (A,B; one-way ANOVA, Tukey's test). Error bars represent SE from two (B) to three $\mathbf{( A )}$ independent trials, $n=40$ per trial in all experiments.
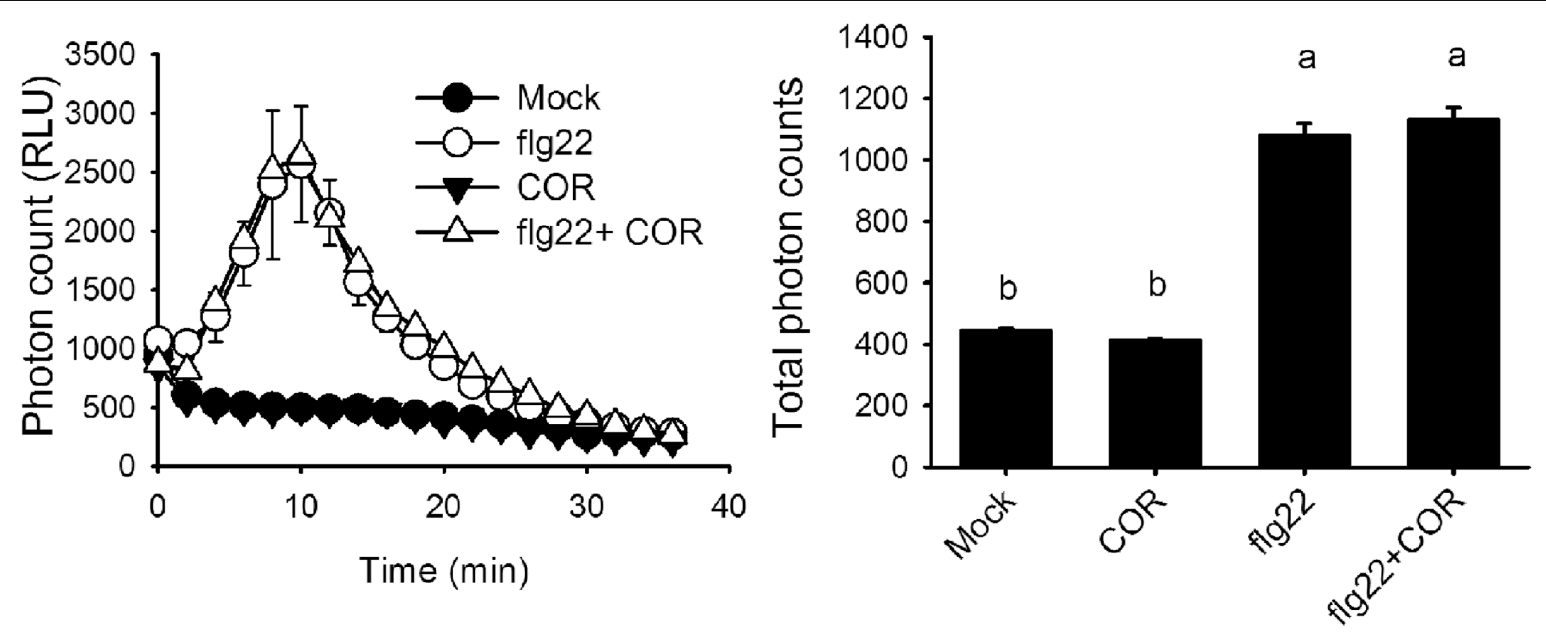

FIGURE 2 | Coronatine does not affect ROS induction by flg22 in leaf disks. Coronatine (COR, $1.56 \mu \mathrm{M})$ did not prevent ROS induction by flg22 ( $1 \mu \mathrm{M})$ in leaf disks. ROS were measured by the peroxidase luminol enhanced chemiluminescence method and are expressed as relative light units (RLU). Values are averages of total photon counts from each treatment. Different letters indicate significant differences at $p<0.01$ (one-way ANOVA, Tukey's test). Error bars represent SE from three independent trials, $n=12$ per trial.

be scavenged by epinephrine itself, leading to the formation of adrenochrome (Misra and Fridovich, 1972). We observed that coronatine failed to prevent the autoxidation of epinephrine, thus indicating that it does not act by scavenging superoxide anions (Supplementary Figure S2). We also found that coronatine cannot prevent stomatal closure induced by exogenously applied $\mathrm{H}_{2} \mathrm{O}_{2}$ (Figure 3A), a result consistent with the predicted inhibitory effect of coronatine on NADPH oxidases, which also implies that this compound is unlikely to act as a $\mathrm{H}_{2} \mathrm{O}_{2}$ scavenger. Next, we investigated the effect of coronatine on promotion of closure by darkness, which requires NADPH oxidases (Desikan et al., 2004). We observed that stomatal closure by darkness is impaired by treatment with the NADPH oxidase inhibitor DPI or in atrbohd and atrbohd/f mutants, but not by the peroxidase inhibitor SHAM (Figures 3B,C). ABA can partially close stomata in the presence of the NADPH oxidase inhibitor DPI or in the double NADPH oxidase mutant atrbohd/f, something which is believed to be due to redundancy of the complex ABA signaling network (Kwak et al., 2003). Consistently with this hypothesis, ABA closed stomata in this double mutant to a similar extent either in the absence or in the presence of coronatine (Figure 3D), thus showing that the presence of these $\mathrm{NADPH}$ oxidases is required for the effect of coronatine on stomata. However, the single atrbohd mutant, which displays 

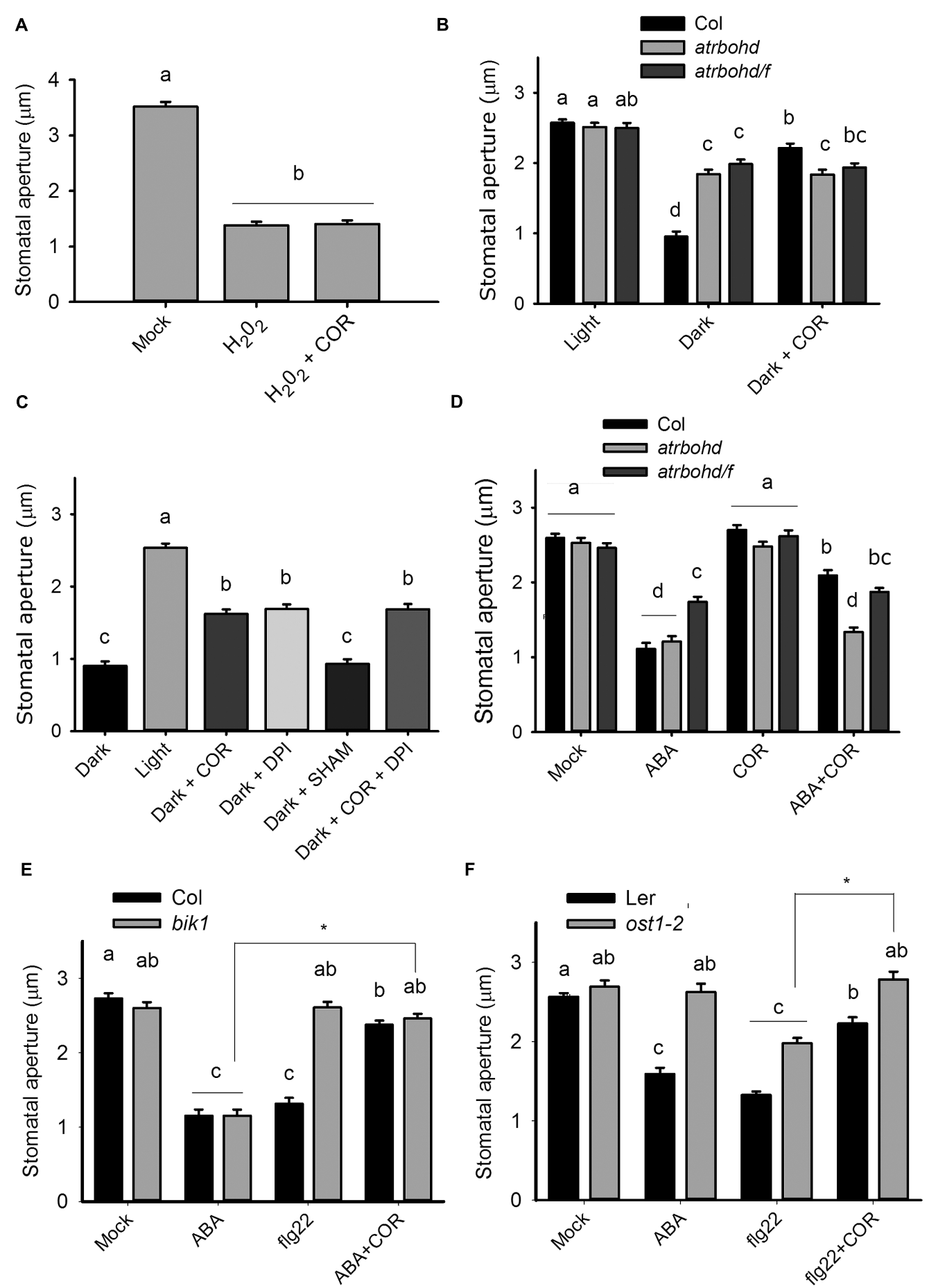

FIGURE 3 | The effect of coronatine on stomatal closure requires ROS production by NADPH oxidases but does not depend on OST1 and BIK1 kinases. (A) Coronatine (COR, $1.56 \mu \mathrm{M})$ could not inhibit stomatal closure induced by $\mathrm{H}_{2} \mathrm{O}_{2}(100 \mu \mathrm{M})$. Stomatal apertures were measured $1.5 \mathrm{~h}$ after application of the respective treatment. (B) atrbohd and atrbohd/f mutants are partially impaired in darkness-induced stomatal closure and coronatine (COR, $1.56 \mu \mathrm{M})$ failed to further inhibit it. (C) Coronatine (COR, $1.56 \mu \mathrm{M})$, DPI (20 $\mu \mathrm{M})$ but not SHAM (2 mM) inhibited darkness-induced stomatal closure (D) Coronatine (COR, $1.56 \mu \mathrm{M})$ failed to inhibit promotion of closure by ABA $(20 \mu \mathrm{M})$ in atrbohd and atrbohd/f mutants but not in Col. (E) bik1 mutant is sensitive to coronatine (COR, $1.56 \mu \mathrm{M})$ for ABA-induced stomatal closure. (F) ost1-2 mutant is sensitive to coronatine (COR, $1.56 \mu \mathrm{M}$ ) for flg22-induced stomatal closure. In (B,C) coronatine, DPI or SHAM were added at the beginning of the incubation with buffer 10/10 for $2 \mathrm{~h}$. In (A) and (D-F) coronatine was added 10 min before the respective treatments. Different letters indicate significant differences at $p<0.05$ in (B) and (D-F; two-way ANOVA) and (A,C; one-way ANOVA, Tukey's test). Datasets marked with asterisks are significantly different as assessed by ANOVA test, ${ }^{*} p<0.05$. Error bars represent SE from two (A,B) and (D-F) or three (C) independent trials, $n=40$ per trial in all experiments. 
a normal response to $\mathrm{ABA}$ but is unable to close stomata in response to flg22 (Kwak et al., 2003; Macho et al., 2012), was also unresponsive to coronatine for promotion of closure by ABA (Figure 3D). This result was unexpected, as we hypothesized that in atrbohd mutants coronatine should still inhibit AtRBOHF and thus partially reduce closure induced by the hormone in atrbohd. By contrast, mutations affecting kinases OST1 and BIK1, which respectively, phosphorylate and activate AtRBOHF (Sirichandra et al., 2009) and AtRBOHD (Kadota et al., 2014), do not affect sensitivity to coronatine for stomatal closure induced by flg22 in the case of ost1-2, and by ABA in the case of bik1 (Figures 3E,F).

\section{Coronatine Reveals a Possible Regulation of ROS on ABA Signaling Components in Guard Cells}

Because of the insensitivity to coronatine of atrbohd, we hypothesized that abnormal ROS synthesis in this mutant might lead to alterations in the ABA signaling network. To investigate this possibility, we tested the ability of coronatine to inhibit ABAinduced stomatal closure in other mutants which, like atrbohd, are also affected in sensitivity to flg22 but not to ABA. For this purpose, we used mpk6, mpk3 (Montillet et al., 2013), npr1-3 (Zeng and He, 2010), and lecrkVI.2-1 (Singh et al., 2012). We observed that in all these mutants, like in atrbohd, this toxin was unable to inhibit closure induced by ABA (Figure 4A). As coronatine inhibits ROS production triggered by ABA in wild type plants, we predicted that in coronatine-insensitive mutants ABA-induced ROS synthesis in stomata would not be affected. However, we observed that coronatine did inhibit ABA-induced ROS production in $m p k 3, m p k 6, n p r 1-3$, and lecrkVI.2-1 mutants in a similar way as in wild type plants (Figure 4B), indicating that they are affected downstream or independently from NADPH oxidase-dependent ROS production. Consistent with the role of COI1 as a receptor of coronatine, no inhibitory effect of this toxin on stomatal closure or in guard cell ROS production was observed in coi1-16 mutant (Figures 4A,B). These results suggest that mpk3, mpk6, npr1-3, and lecrkVI.2-1 mutants possess the ability to close stomata in response to ABA to the same extent as wild type plants without a requirement of ROS synthesis. In order to further test this possibility, we studied the effect of the NADPH oxidase inhibitor DPI on ABA-induced closure in these mutants and found that, similarly to coronatine, this compound inhibits closure triggered by the hormone in wild type but not in mpk3, mpk6, npr1-3, or lecrkVI.2-1 mutants (Figure 4C). Consistent with an impairment of ROS signaling in these mutants, they all showed reduced sensitivity to exogenously applied $\mathrm{H}_{2} \mathrm{O}_{2}$ (Supplementary Figure S3). Interestingly, coi1-16 mutant also closed stomata in the presence of DPI, suggesting that it may also be affected in ROS signaling, which may be linked to the fact that COI1 is required for NADPH oxidase regulation by coronatine. Nevertheless, unlike mpk3, mpk6, npr1-3, and lecrkVI.2-1, coil-16 sensitivity to exogenous $\mathrm{H}_{2} \mathrm{O}_{2}$ is not affected (Supplementary Figure S3). When $0.5 \mu \mathrm{M}$ instead of $20 \mu \mathrm{M}$ ABA was used, mpk3, mpk6, npr1-3, and lecrkVI.2-1 showed different degrees of insensitivity to the hormone, which indicates abnormal ABA signaling in these mutants (Figure 4D), thus suggesting that proteins affected by such mutations play some role in the transduction of ROS generated by ABA in guard cells. Interestingly, in the two mutants which displayed some degree of sensitivity to $0.5 \mu \mathrm{M}$ ABA, npr1-3, and lecrk-VI.21 , coronatine was capable of reducing closure triggered by this low concentration of the hormone (Figure 4D). This result suggests that at least in npr1-3 and lecrk-VI.2-1 at low ABA concentrations the putative signaling components upregulated by reduced ROS signaling play a less dominant role, so that ROS signaling is more important and therefore coronatine significantly affects closure triggered by low concentrations of ABA. Consistently with this possibility, as noted above, $m p k 3$, mpk6, npr1-3, and lecrk-VI.2-1 display only partially impaired sensitivity to exogenous $\mathrm{H}_{2} \mathrm{O}_{2}$ in stomatal closure. Unlike the rest of the tested mutants, rbohd behaved in a similar way at 20 and $0.5 \mu \mathrm{M}$ ABA, with similar sensitivity to ABA and complete insensitivity to coronatine (Figure 4D). This could be related to the fact that AtRBOHD is involved in ROS synthesis but not in signaling, as likely is the case of the other four mutants. Since it has been shown that both overexpression of the RCAR3 ABA receptor and mutation of the gene encoding its interacting phosphatase PP2CA also cause loss of sensitivity to coronatine for ABA-induced stomatal closure (but not reduction in sensitivity to flg22; Lim et al., 2014), we hypothesized that, according to our model of action of coronatine, these transgenic lines and mutants would also be affected in sensitivity to the NADPH oxidase inhibitor DPI. We observed that this is the case for $p p 2 c a-1$ mutant, indicating that the reason of stomatal insensitivity to coronatine of this mutant is likely a defect in ROS signaling of synthesis (Figure 4E). When 1 instead of $20 \mu \mathrm{M}$ ABA was used, no effect of DPI was observed either in $p p 2 c a-$ 1 or in wild type plants. Altogether, these results suggest that ROS may negatively regulate ABA signaling components that can compensate for abnormal ROS signaling in mpk3, mpk6, npr1-3 and lecrkVI.2-1, and possibly also in NADPH oxidase mutants atrbohD and atrbohF.

Coronatine interferes also with inhibition of light-induced stomatal opening by flg22 by relieving its inhibitory effect on $\mathrm{K}^{+}{ }_{\text {in }}$ currents (Zhang et al., 2008). Since there is strong evidence indicating that the ABA signaling network is different for inhibition of opening and for promotion of closure (Yin et al., 2013), we tested if mpk3, mpk6, npr1-3, and lecrkVI.2-1 mutants are similarly affected in sensitivity to coronatine in assays of inhibition of light-induced stomatal opening by ABA. Just as observed in promotion of closure experiments, coronatine failed to prevent inhibition of stomatal opening by ABA in npr1-3 and lecrkVI.2-1 (Figure 4F). As previously reported, $m p k 3$ mutants (Gudesblat et al., 2007), and also mpk6, displayed partial insensitivity to ABA for inhibition of lightinduced stomatal opening. Both mutants were only partially insensitive to coronatine. As expected, coil-16 mutants were also insensitive to coronatine, and responded like wild type to ABA. These results indicate that the signaling components affected by coronatine which are required for ROS synthesis are active in both promotion of closure and inhibition of opening by ABA. 
A

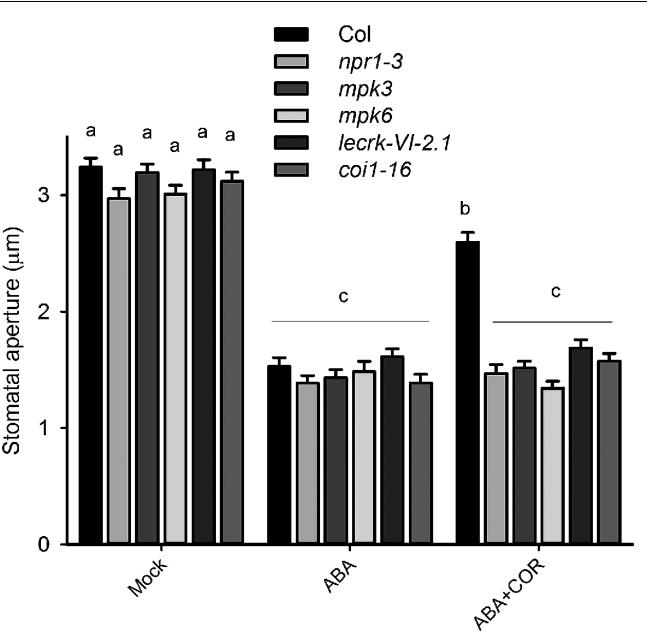

C

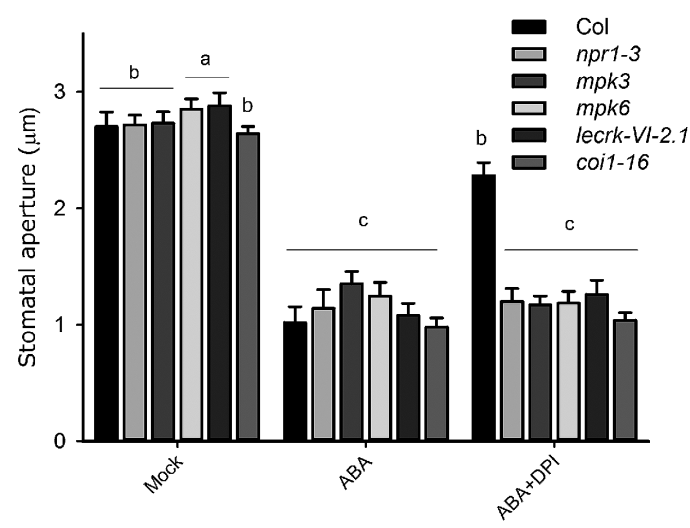

$\mathbf{E}$

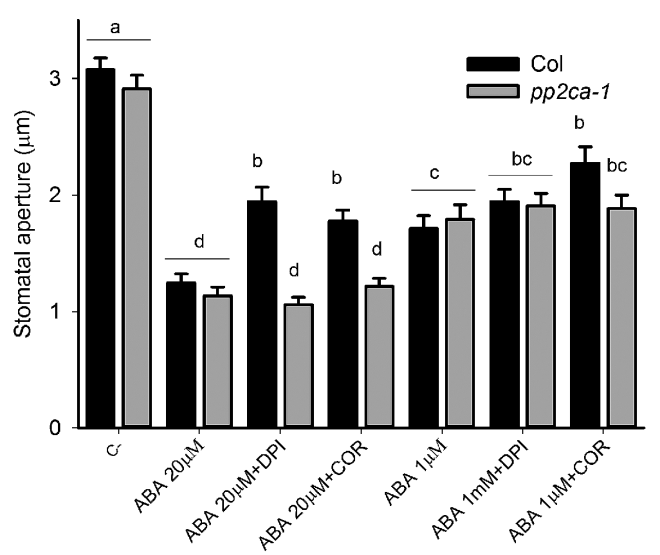

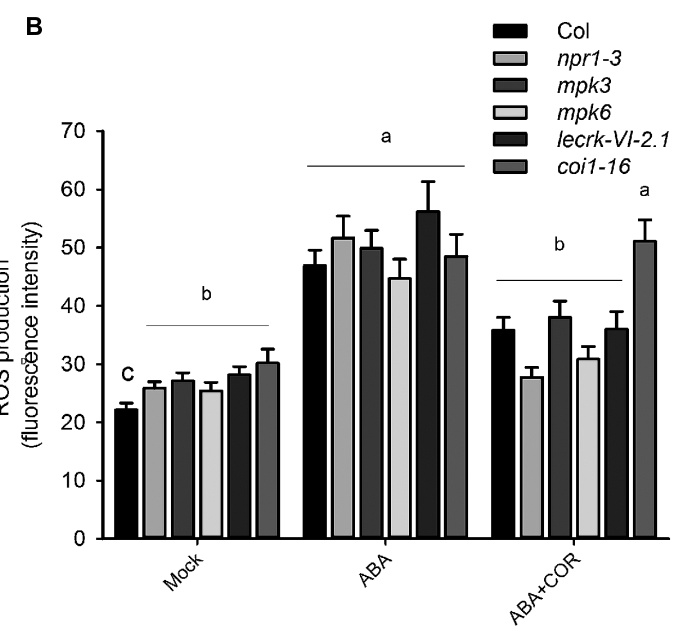

D

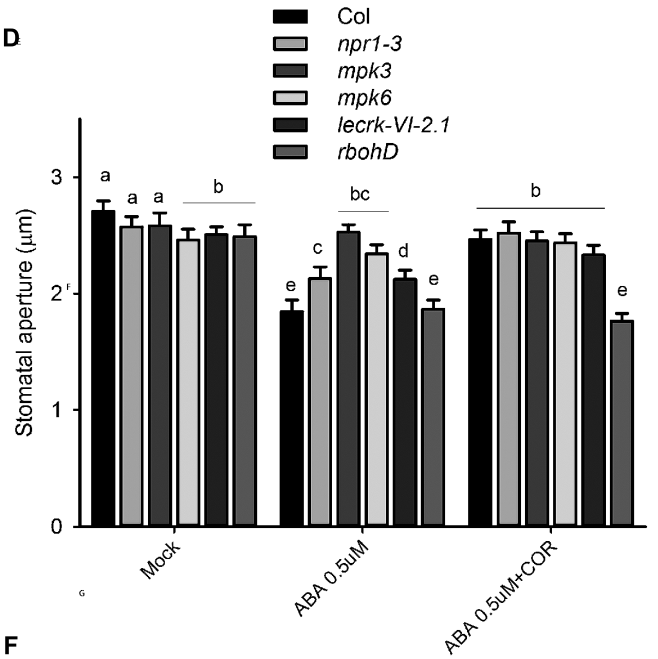

$\mathbf{F}$

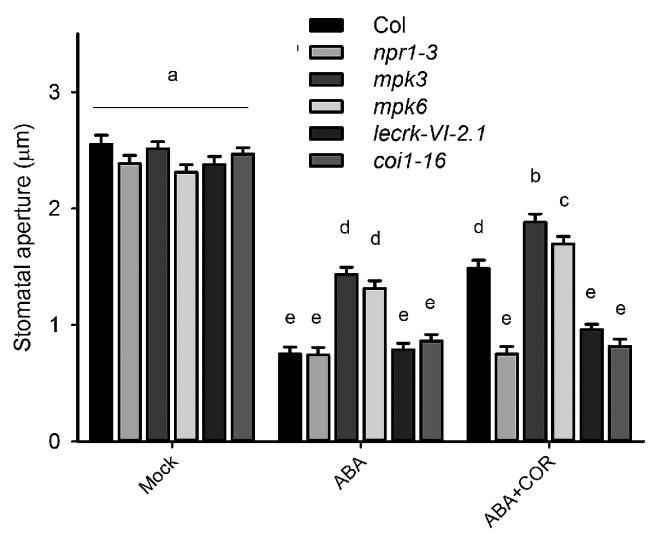

FIGURE 4 | Several mutants display reduced stomatal sensitivity to coronatine and DPI. (A) Coronatine (COR, $1.56 \mu \mathrm{M}$ ) failed to inhibit stomatal closure by ABA $(20 \mu \mathrm{M})$ in mpk3, mpk6, npr1-3 and lecrkVI-2.1, and coi1-16 mutants. (B) Coronatine (COR, $1.56 \mu \mathrm{M})$ inhibited ABA (20 $\mu$ M)-induced ROS production in guard cells of mpk3, mpk6, npr1-3, and lecrkVI-2-1 mutants. (C) Treatment with DPI (20 $\mu$ M) failed to interfere with stomatal closure induced by ABA (20 $\mu$ M) in $n p r 1-3$, mpk3, mpk6, and lecrkVI-2-1 mutants but not in wild type Col. (D) mpk3, mpk6, npr1-3, and lecrkVI.2-1 showed different degrees of insensitivity to ABA (0.5 $\mu \mathrm{M}$ ). At this lower ABA concentration, coronatine (COR, $1.56 \mu \mathrm{M})$ prevented stomatal closure in npr1-3 and lecrkVI.2-1 mutants. (E) pp2ca-1 mutant is insensitive to coronatine $(\mathrm{COR}, 1.56 \mu \mathrm{M})$ and DPI $(20 \mu \mathrm{M})$ in stomatal closure induced by $20 \mu \mathrm{M}$ ABA. (F) Coronatine (COR, $1.56 \mu \mathrm{M})$ partially relieved inhibition of light-induced stomatal opening by ABA $(20 \mu \mathrm{M})$ in mpk3, mpk6, but not in npr1-3 and lecrkVI-2-1 mutants. DPI was added to the incubation buffer 10 min prior to ABA (20 $\mu \mathrm{M})$. In (A,B) and (D-F) coronatine was added $10 \mathrm{~min}$ before ABA. In all cases stomatal apertures were measured $1.5 \mathrm{~h}$ after treatments. Different letters indicate significant differences at $p<0.05$ in (A-F; two-way ANOVA). Error bars represent SE from two independent trials, $n=40$ per trial (A-F). 


\section{DISCUSSION}

Our results show a mechanism through which coronatine, a phytotoxin produced by the pathogenic bacterium Pst DC3000, hijacks stomatal immunity, through inhibition of guard cell NADPH oxidase-dependent ROS production. Coronatine inhibits closure by flg22, ABA and darkness, which trigger ROS production through NADPH oxidases. However, it does not affect peroxidase-dependent ROS production or stomatal closure triggered by $\mathrm{SA}$, which promotes stomatal closure through apoplastic peroxidases. In addition, coronatine does not inhibit the oxidative burst triggered by flg22 in leaf disks, suggesting that it affects a guard-cell specific regulatory mechanism of AtRBOHD and AtRBOHF, and that it does not directly inhibit their enzymatic activity. NADPH oxidases generate as a reaction product the short lived superoxide anion, which is enzymatically dismutated into the more stable $\mathrm{H}_{2} \mathrm{O}_{2}$ derivative that is required for a viable long-range cell-to-cell signal, for passing membranes or for accumulation. This step occurs very quickly and is catalyzed by superoxide dismutase (Sagi and Fluhr, 2006). Thus an inhibitory effect of coronatine on superoxide dismutases cannot be completely ruled out. By contrast, coronatine does not appear to act as a ROS scavenger, as it cannot prevent stomatal closure by exogenously applied $\mathrm{H}_{2} \mathrm{O}_{2}$ or in vitro epinephrine autoxidation, which generates superoxide anion.

Reactive oxygen species act as important signaling hubs in guard cell signaling (Baxter et al., 2014; Kollist et al., 2014), and therefore their concentration is tightly regulated. NADPH oxidases AtRBOHD and AtRBOHF have been shown to be regulated in multiple ways, including direct binding of $\mathrm{Ca}^{2+}$ (Ogasawara et al., 2008) and phosphatidic acid (Zhang and Du, 2009), and phosphorylation by OST1/SnRK2.6 (Sirichandra et al., 2009), CBL-interacting protein kinase CIPK26 (Drerup et al., 2013), calcium dependent protein-kinase 5 (Dubiella et al., 2013) and the kinase BIK1, which is part of the receptor complex for several MAMPs (Kadota et al., 2014; Li et al., 2014). Coronatine could thus interfere with some of these regulatory mechanisms to regulate NADPH oxidase activity in guard cells. Mutations in BIK1 and OST1 do not affect sensitivity to coronatine, which seems to rule out the possibility that the effect of the toxin is mediated by these kinases. Consistently with our findings, it has been reported that coronatine reversed the inhibitory effect of flg22 on guard cell $\mathrm{K}^{+}$in currents (Zhang et al., 2008), which in turn are negatively regulated by $\mathrm{H}_{2} \mathrm{O}_{2}$ (Kohler et al., 2003).

Coronatine facilitates Pst DC3000 invasion in several ways, including inhibition of stomatal immunity, promotion of bacterial multiplication and persistence inside the plant. It also causes induction of disease symptoms, enhancement of disease susceptibility in uninfected parts of the plant, inhibition of cell wall defenses and a delay in hypersensitive response cell death (Lee et al., 2013; Xin and He, 2013; Gimenez-Ibanez et al., 2016). However, none of these effects of coronatine have been linked to inhibition of NADPH oxidase-dependent ROS synthesis. Instead, coronatine treated plants displayed increased ROS production after $24 \mathrm{~h}$ both in tomato (Ishiga et al., 2009) and in A. thaliana (Camanes et al., 2012) whole leaves. Recently it has been shown that coronatine strongly induces the expression of N-ACETYLTRANSFERASE ACTIVITY1 (NATA1), which leads to decreased defenserelated $\mathrm{H}_{2} \mathrm{O}_{2}$ accumulation through interference with polyamine metabolism (Lou et al., 2016). However, this effect occurs a few hours after coronatine treatment, while the effect of coronatine on stomata is very fast. Interestingly, some pathogen effectors have been shown to promote virulence by interfering with ROS induction. For example, the Ustilago maydis fungal effector Pep1, contributes to the penetration of the host epidermis by inhibiting apoplastic plant peroxidases (Hemetsberger et al., 2012), while the Phytophthora sojae effector CRN 115 decrease $\mathrm{H}_{2} \mathrm{O}_{2}$ accumulation during infection through interaction with plant catalases (Zhang et al., 2015).

Testing of coronatine on stomata of different mutants affected in stomatal responses to flg22 but not to ABA in order to better understand the mechanism of action of the toxin allowed us to find unexpected responses to this hormone in them. The double NADPH oxidase mutant atrbohd/f, incapable of synthesizing ROS in stomata in response to ABA (Kwak et al., 2003), is insensitive to coronatine, consistently with the proposed inhibitory effect of this toxin on ROS production by NADPH oxidases. However, the single mutant atrbohd, affected in stomatal response to flg22 but not to ABA, turned out to be unresponsive to coronatine for ABA-induced promotion of closure. This finding surprised us, since we reasoned that inhibition of intact AtRBOHF by coronatine in atrbohd should cause reduced stomatal response of this mutant to ABA. Previous reports have described unexpected phenotypes in atrbohd mutant, which display constitutive or inducible over-activation of immunity (reviewed in Kadota et al., 2015). In order to test whether lack of response to coronatine is specific of atrbohd, or if by contrast it is also found in other mutants unresponsive to MAMPs in guard cells, we analyzed mpk3, mpk6, npr1-3, and lecrkVI.2-1 mutants, which like atrbohd, are affected in stomatal sensitivity to ABA but not to flg22. Similarly to atrbohd, they also displayed insensitivity not only to coronatine but also to the NADPH oxidase inhibitor DPI for promotion of closure by ABA. This hormone was capable of inducing ROS synthesis in guard cells of all four mutants and, somewhat surprisingly, coronatine was still capable of inhibiting it, even when the toxin could not inhibit the stomatal response to the hormone in the mutants. These findings made us suspect that, unlike wild type plants, mpk3, mpk6, npr1-3, and lecrkVI.2-1 mutants do not require ROS for ABA-induced promotion of closure. This hypothesis was strengthened by the reduced sensitivity to stomatal closure triggered by exogenous $\mathrm{H}_{2} \mathrm{O}_{2}$ in these mutants, a result suggesting that MPK3, MPK6, NPR1-3, AND LECRKVI.2-1 are involved in signaling downstream of ROS. Thus, we propose that guard cells ABA signaling components independent of ROS might compensate for defects in ROS synthesis or signaling such as those existing in the analyzed mutants. The synthesis of such ROS-independent signaling components would be negatively regulated by ROS in the long term, and thus upregulated in mpk3, mpk6, npr1-3, and lecrkVI.21, and likely also in atrbohd (Figure 5). Interestingly, it was previously reported that a guard cell-specific $M P K 3$ antisense 


\section{Coronatine}

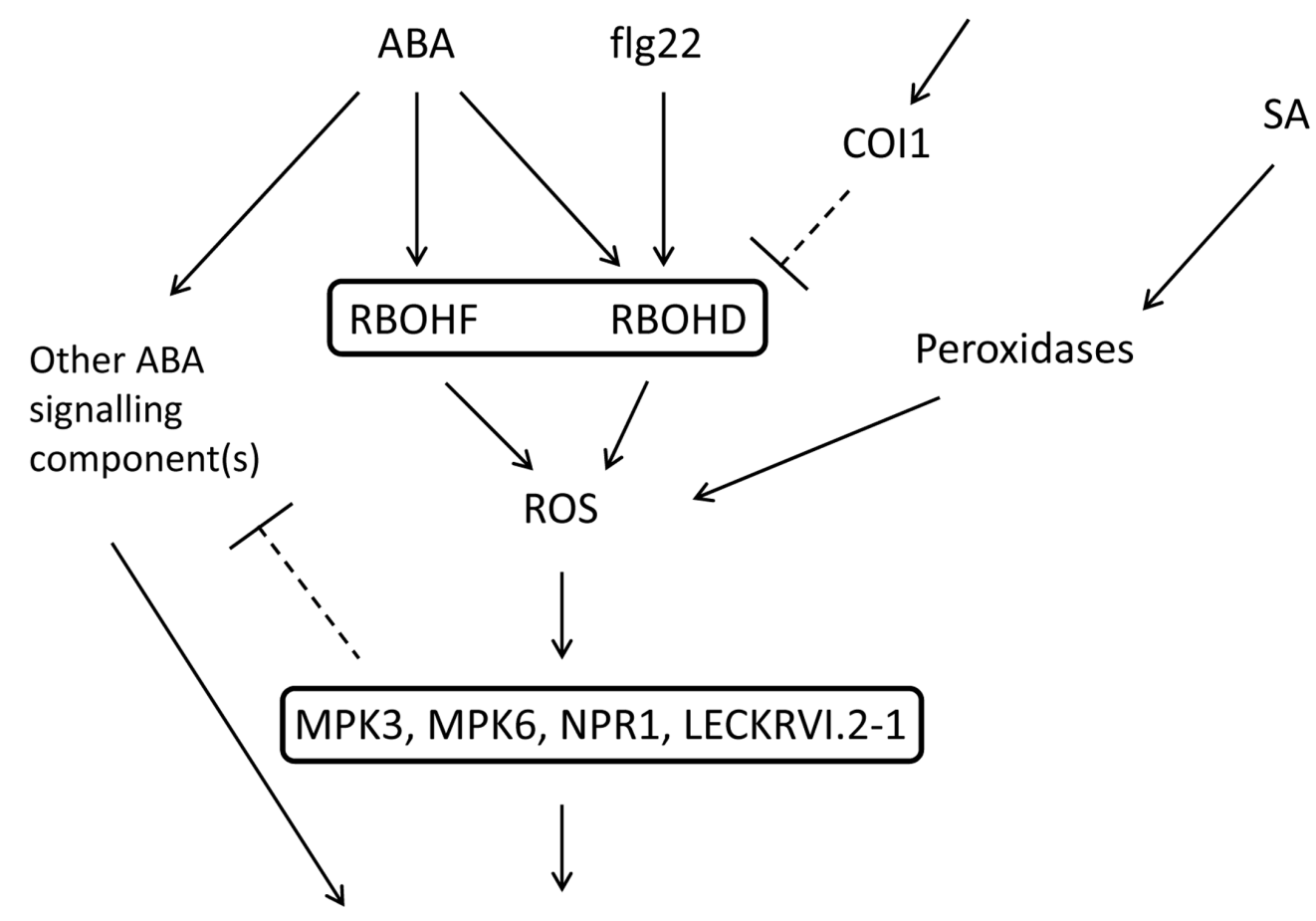

Stomatal closure

FIGURE 5 | Proposed model of ROS inhibition by coronatine in the context of ABA signaling. Coronatine inhibits stomatal closure induced by ABA and flg22 through inhibition of ROS synthesis by NADPH oxidases AtRBOHD and AtRBOHF. This toxin does not affect promotion of stomatal closure by SA, which induces ROS synthesis mediated by peroxidases. In atrbohd, mpk3, mpk6, npr1-3, and lecrkVI-2.1 mutants the sensitivity to ABA is not affected by coronatine or DPI. This might be due to negative regulation by ROS of other ABA signaling components, which would be upregulated in these mutants. Thus in these mutants $A B A$ is able to close stomata in the absence of ROS signaling.

mutant, displaying a stomatal phenotype similar to the $m p k 3$ mutant used in this work, is insensitive to inhibition of ABAinduced stomatal closure by a virulence factor secreted by Xanthomonas campestris pv. campestris with a similar effect to coronatine on stomata (Gudesblat et al., 2009). Reduced sensitivity to coronatine was also observed for inhibition of opening by $\mathrm{ABA}$, even when signaling in this process differs from that of promotion of closure by the same hormone (Yin et al., 2013). Interestingly, $m p k 3$ and $m p k 6$ mutants were partially insensitive to ABA, a phenotype previously reported in guard cell-specific MPK3-antisense lines (Gudesblat et al., 2007). In both mutants coronatine can further reduce ABA sensitivity, suggesting that the diminished sensitivity of $m p k 3$ and $m p k 6$ to ABA is in part independent of the NADPH oxidases targeted by coronatine. Further support for our proposal that coronatine affects ROS synthesis comes from the insensitivity of $p p 2 c a-1$ mutant to the NADPH oxidase inhibitor DPI. Unlike $m p k 3$, mpk6, npr1-3 and lecrkVI.2-1, pp2ca-1 is exclusively affected in $\mathrm{ABA}$ signaling, and has been shown to display a wild type stomatal respose to flg22 (Lim et al., 2014). Thus, while the insensitivity to coronatine of $p p 2 c a-1$ has probably a different origin than that of $m p k 3, m p k 6, n p r 1-3$, and lecrkVI.2-1, still all of them share DPI insensitivity, strongly linking the effect of coronatine to NADPH-dependent ROS signaling. pp2ca-1 mutants are hypersensitive to $\mathrm{ABA}$ in promotion of stomatal closure (Kuhn et al., 2006), which suggests that increased ABA signaling in this mutant somehow inhibits either stomatal ROS production in response to the hormone or sensitivity to them (Kuhn et al., 2006).

How MPK3, MPK6, NPR1, and LECKVI.2 might precisely act in ABA and MAMP signaling is not completely clear, but this possibility is strengthened by our observation that mutants affected in all four of them displayed reduced sensitivity to ABA when $0.5 \mu \mathrm{M}$ instead of $20 \mu \mathrm{M}$ was used. MPK3 and MPK6 are generally believed to act downstream of ROS signaling, however, there is also evidence that these enzymes might act upstream or independently from ROS (reviewed in Jalmi and Sinha, 2015). NPR1 is a transcription factor essential for SA signaling which has previously been proposed to act upstream of $\mathrm{ABA}$, given that $\mathrm{ABA}$ biosynthesis is required for SA-mediated stomatal closure (Zeng and He, 2010). It has also been proposed that coronatine inhibits stomatal closure through inhibition of SA synthesis (Zheng et al., 2012), but our results do not support this hypothesis, as coronatine still inhibits ROS induction by ABA even when SA signaling is disrupted in npr1-3 mutants in guard cells. Furthermore, these 
mutants display reduced sensitivity to low concentrations of the hormone, which would not be expected if NPR1 acts upstream of ABA synthesis. LECRKVI.2 is an L-type lectin receptor kinase required for flg22-induced MPK3 and MPK6 activation and for pathogen resistance (Singh et al., 2012). How LECRKVI.2 might precisely act in signaling downstream of ROS also needs to be clarified. The loss of function lecrk-V.5 mutants, affected in a related receptor, are less sensitive to coronatine (DesclosTheveniau et al., 2012). This could be due to their enhanced ROS synthesis, which might compensate for the inhibition of ROS production caused by this toxin in guard cells.

The importance of JA signaling network in antagonizing stomatal closure by MAMPs is highlighted by the fact that Pseudomonas syringae pv. tabaci effector HopX1 inhibits stomatal closure through activation of JA signaling by promoting the degradation of JASMONATE ZIM-domain transcriptional repressors proteins (JAZ), and can complement a Pst coronatine deficient strain (Gimenez-Ibanez et al., 2014). Recently it has also been shown that the Pst effector protein AvrB can rescue the capacity of opening stomata of a Pst coronatine deficient strain in a COI1-dependent manner (Zhou et al., 2015). However, while it is clear that coronatine inhibit stomatal closure triggered by flg22 and ABA, evidence regarding the effect of jasmonates on stomata is conflicting. While some reports have shown that MeJA promotes stomatal closure (Gehring et al., 1997; Suhita et al., 2004), other groups have found either no effect of this compound on stomatal closure (Zhao et al., 2008), or an inhibitory effect on flg22-induced stomatal closure in a JA signaling-independent manner (Montillet et al., 2013). Although different jasmonate forms exist in plants, only the conjugate JA-Ile and its structural analog coronatine produced by Pst are known to be biologically active. Both of them, but not racemic ( \pm ) JA, can promote opening of dark-closed Ipomoea tricolor stomata (Okada et al., 2009). It might thus be possible that under different environmental conditions or in different tissues MeJA or other jasmonates are conjugated differently inside the cell, leading to compounds with different activities.

Our work shows that coronatine exerts its inhibitory effect on stomata by affecting ROS synthesis mediated by NADPH oxidases AtRBOHD and AtRBOHF and thus reinforces the important role of NADPH oxidases in guard cell signaling.

\section{REFERENCES}

Alonso, J. M., Stepanova, A. N., Leisse, T. J., Kim, C. J., Chen, H., Shinn, P., et al. (2003). Genome-wide insertional mutagenesis of Arabidopsis thaliana. Science 301, 653-657. doi: 10.1126/science.1086391

Arnaud, D., and Hwang, I. (2014). A sophisticated network of signaling pathways regulates stomatal defenses to bacterial pathogens. Mol Plant 8, 566-581. doi: 10.1016/j.molp.2014.10.012

Baxter, A., Mittler, R., and Suzuki, N. (2014). ROS as key players in plant stress signalling. J. Exp. Bot. 65, 1229-1240. doi: 10.1093/jxb/ert375

Bolwell, G. P. (1999). Role of active oxygen species and NO in plant defence responses. Curr. Opin. Plant Biol. 2, 287-294. doi: 10.1016/S1369-5266(99) 80051-X

Camanes, G., Pastor, V., Cerezo, M., Garcia-Andrade, J., Vicedo, B., GarciaAgustin, P., et al. (2012). A deletion in NRT2.1 attenuates Pseudomonas syringae-induced hormonal perturbation, resulting in primed plant defenses. Plant Physiol. 158, 1054-1066. doi: 10.1104/pp.111.184424
Understanding how coronatine precisely causes this effect might help to develop strategies to prevent the entry of Pst through stomata.

\section{AUTHOR CONTRIBUTIONS}

GG and LT conceived the idea of this work, executed experiments, and wrote the manuscript. MB and SG designed and executed superoxide measurement experiments. AV and PT contributed with discussion and critical comments. All authors approved the final version.

\section{FUNDING}

This work was supported by grants PIP CONICET 2012 - 2014 00677, PICT 2013-2016 1045, and PICT 2015-2017 3286.

\section{ACKNOWLEDGMENTS}

AV, GG, and PT are Career Investigators of CONICET, LT was supported by a doctoral scholarship from CONICET. We are grateful to Sheng Yang He (Michigan University, USA) for Pst DC3118, Cyril Zipfel (Sainsbury Laboratory, United Kingdom) for providing atrbohd, atrbohd/f, and bik1, Alain Goosens (VIB-Ghent University, Belgium) for coi1-16, Laurent Zimmerli for lecrkVI-2.1, Rita Ulloa (INGEBI, Argentina) for npr1-3, Irene Baroli (University of Buenos Aires, Argentina) for ost1-2, Miguel Gonzalez-Guzmán (CIB,Spain) for pp2ca1, and Fernando Pieckenstain (INTECH, University of San Martín, Argentina) for $m p k 3$ and $m p k 6$. We thank Javier Moreno and Irene Baroli for critical reading of this manuscript.

\section{SUPPLEMENTARY MATERIAL}

The Supplementary Material for this article can be found online at: http://journal.frontiersin.org/article/10.3389/fpls.2016.01851/ full\#supplementary-material

Cao, H., Glazebrook, J., Clarke, J. D., Volko, S., and Dong, X. (1997). The Arabidopsis NPR1 gene that controls systemic acquired resistance encodes a novel protein containing ankyrin repeats. Cell 88, 57-63. doi: 10.1016/S00928674(00)81858-9

Cutler, S. R., Rodriguez, P. L., Finkelstein, R. R., and Abrams, S. R. (2010). Abscisic acid: emergence of a core signaling network. Annu. Rev. Plant Biol. 61, 651-679. doi: 10.1146/annurev-arplant-042809-112122

Desclos-Theveniau, M., Arnaud, D., Huang, T. Y., Lin, G. J., Chen, W. Y., Lin, Y. C., et al. (2012). The Arabidopsis lectin receptor kinase LecRK-V.5 represses stomatal immunity induced by Pseudomonas syringae pv. tomato DC3000. PLoS Pathog. 8:e1002513. doi: 10.1371/journal.ppat.1002513

Desikan, R., Cheung, M., Clarke, A., Golding, S., Sagi, M., Fluhr, R., et al. (2004). Hydrogen peroxide is a common signal for darkness- and ABA-induced stomatal closure in Pisum sativum. Funct. Plant Biol. 31, 913-920. doi: 10.1071/ FP04035

Drerup, M. M., Schlucking, K., Hashimoto, K., Manishankar, P., Steinhorst, L., Kuchitsu, K., et al. (2013). The Calcineurin B-like calcium sensors CBL1 
and CBL9 together with their interacting protein kinase CIPK26 regulate the Arabidopsis NADPH oxidase RBOHF. Mol. Plant 6, 559-569. doi: 10.1093/mp/ sst009

Du, M., Zhai, Q., Deng, L., Li, S., Li, H., Yan, L., et al. (2014). Closely related NAC transcription factors of tomato differentially regulate stomatal closure and reopening during pathogen attack. Plant Cell 26, 3167-3184. doi: 10.1105/tpc. 114.128272

Dubiella, U., Seybold, H., Durian, G., Komander, E., Lassig, R., Witte, C. P., et al. (2013). Calcium-dependent protein kinase/NADPH oxidase activation circuit is required for rapid defense signal propagation. Proc. Natl. Acad. Sci. U.S.A. 110, 8744-8749. doi: 10.1073/pnas.1221294110

Egoshi, S., Takaoka, Y., Saito, H., Nukadzuka, Y., Hayashi, K., Ishimaru, Y., et al. (2016). Dual function of coronatine as a bacterial virulence factor against plants: possible COI1-JAZ-independent role. RSC Adv. 6, 19404-19412. doi: 10.1039/ C5RA20676F

Ellis, C., and Turner, J. G. (2002). A conditionally fertile coil allele indicates crosstalk between plant hormone signalling pathways in Arabidopsis thaliana seeds and young seedlings. Planta 215, 549-556. doi: 10.1007/s00425-002-0787-4

Gehring, C., Irving, H., Mcconchie, R., and Parish, R. (1997). Jasmonates induce intracellular alkalinization and closure of Paphiopedilum guard cells. Ann. Bot. 80, 485-489. doi: 10.1006/anbo.1997.0471

Geng, X., Jin, L., Shimada, M., Kim, M. G., and Mackey, D. (2014). The phytotoxin coronatine is a multifunctional component of the virulence armament of Pseudomonas syringae. Planta 240, 1149-1165. doi: 10.1007/s00425-0142151-x

Gimenez-Ibanez, S., Boter, M., Fernandez-Barbero, G., Chini, A., Rathjen, J. P., and Solano, R. (2014). The bacterial effector HopX1 targets JAZ transcriptional repressors to activate jasmonate signaling and promote infection in Arabidopsis. PLoS Biol. 12:e1001792. doi: 10.1371/journal.pbio.1001792

Gimenez-Ibanez, S., Hann, D. R., Ntoukakis, V., Petutschnig, E., Lipka, V., and Rathjen, J. P. (2009). AvrPtoB targets the LysM receptor kinase CERK1 to promote bacterial virulence on plants. Curr. Biol. 19, 423-429. doi: 10.1016/j. cub.2009.01.054

Gimenez-Ibanez, S., Chini, A., and Solano, R. (2016). How microbes twist jasmonate signaling around their little fingers. Plants 5:E9. doi: 10.3390/ plants5010009

Gudesblat, G. E., Iusem, N. D., and Morris, P. C. (2007). Guard cell-specific inhibition of Arabidopsis MPK3 expression causes abnormal stomatal responses to abscisic acid and hydrogen peroxide. New Phytol. 173, 713-721. doi: 10.1111/ j.1469-8137.2006.01953.x

Gudesblat, G. E., Torres, P. S., and Vojnov, A. A. (2009). Xanthomonas campestris overcomes Arabidopsis stomatal innate immunity through a DSF cell-to-cell signal-regulated virulence factor. Plant Physiol. 149, 1017-1027. doi: 10.1104/ pp.108.126870

Guzel Deger, A., Scherzer, S., Nuhkat, M., Kedzierska, J., Kollist, H., Brosche, M., et al. (2015). Guard cell SLAC1-type anion channels mediate flagellin-induced stomatal closure. New Phytol. 208, 162-173. doi: 10.1111/nph.13435

Hemetsberger, C., Herrberger, C., Zechmann, B., Hillmer, M., and Doehlemann, G. (2012). The Ustilago maydis effector Pep1 suppresses plant immunity by inhibition of host peroxidase activity. PLoS Pathog. 8:e1002684. doi: 10.1371/ journal.ppat.1002684

Ishiga, Y., Uppalapati, S. R., Ishiga, T., Elavarthi, S., Martin, B., and Bender, C. L. (2009). The phytotoxin coronatine induces light-dependent reactive oxygen species in tomato seedlings. New Phytol. 181, 147-160. doi: 10.1111/j.14698137.2008.02639.x

Jalmi, S. K., and Sinha, A. K. (2015). ROS mediated MAPK signaling in abiotic and biotic stress- striking similarities and differences. Front. Plant Sci. 6:769. doi: 10.3389/fpls.2015.00769

Joshi-Saha, A., Valon, C., and Leung, J. (2011). A brand new START: abscisic acid perception and transduction in the guard cell. Sci. Signal. 4, re4. doi: 10.1126/ scisignal.2002164

Kadota, Y., Shirasu, K., and Zipfel, C. (2015). Regulation of the NADPH oxidase RBOHD during plant immunity. Plant Cell Physiol. 56, 1472-1480. doi: 10. 1093/pcp/pcv063

Kadota, Y., Sklenar, J., Derbyshire, P., Stransfeld, L., Asai, S., Ntoukakis, V., et al. (2014). Direct regulation of the NADPH oxidase RBOHD by the PRRassociated kinase BIK1 during plant immunity. Mol. Cell 54, 43-55. doi: 10. 1016/j.molcel.2014.02.021
Khokon, A. R., Okuma, E., Hossain, M. A., Munemasa, S., Uraji, M., Nakamura, Y., et al. (2011). Involvement of extracellular oxidative burst in salicylic acidinduced stomatal closure in Arabidopsis. Plant Cell Environ. 34, 434-443. doi: 10.1111/j.1365-3040.2010.02253.x

Khokon, M. A., Hossain, M. A., Munemasa, S., Uraji, M., Nakamura, Y., Mori, I. C., et al. (2010a). Yeast elicitor-induced stomatal closure and peroxidasemediated ROS production in Arabidopsis. Plant Cell Physiol. 51, 1915-1921. doi: $10.1093 / \mathrm{pcp} / \mathrm{pcq} 145$

Khokon, M. A., Uraji, M., Munemasa, S., Okuma, E., Nakamura, Y., Mori, I. C., et al. (2010b). Chitosan-induced stomatal closure accompanied by peroxidasemediated reactive oxygen species production in Arabidopsis. Biosci. Biotechnol. Biochem. 74, 2313-2315. doi: 10.1271/bbb.100340

Kim, T. H., Bohmer, M., Hu, H., Nishimura, N., and Schroeder, J. I. (2010). Guard cell signal transduction network: advances in understanding abscisic acid, CO2, and Ca2+ signaling. Annu. Rev. Plant Biol. 61, 561-591. doi: 10.1146/annurevarplant-042809-112226

Kohler, B., Hills, A., and Blatt, M. R. (2003). Control of guard cell ion channels by hydrogen peroxide and abscisic acid indicates their action through alternate signaling pathways. Plant Physiol. 131, 385-388. doi: 10.1104/pp.016014

Kollist, H., Nuhkat, M., and Roelfsema, M. R. (2014). Closing gaps: linking elements that control stomatal movement. New Phytol. 203, 44-62. doi: 10. $1111 /$ nph.12832

Kuhn, J. M., Boisson-Dernier, A., Dizon, M. B., Maktabi, M. H., and Schroeder, J. I. (2006). The protein phosphatase AtPP2CA negatively regulates abscisic acid signal transduction in Arabidopsis, and effects of abh1 on AtPP2CA mRNA. Plant Physiol. 140, 127-139. doi: 10.1104/pp.105.070318

Kwak, J. M., Mori, I. C., Pei, Z. M., Leonhardt, N., Torres, M. A., Dangl, J. L., et al. (2003). NADPH oxidase AtrbohD and AtrbohF genes function in ROSdependent ABA signaling in Arabidopsis. EMBO J. 22, 2623-2633. doi: 10.1093/ emboj/cdg277

Lee, S., Ishiga, Y., Clermont, K., and Mysore, K. S. (2013). Coronatine inhibits stomatal closure and delays hypersensitive response cell death induced by nonhost bacterial pathogens. PeerJ 1: e34. doi: 10.7717/peerj.34

Li, L., Li, M., Yu, L., Zhou, Z., Liang, X., Liu, Z., et al. (2014). The FLS2-associated kinase BIK1 directly phosphorylates the NADPH oxidase RbohD to control plant immunity. Cell Host Microbe 15, 329-338. doi: 10.1016/j.chom.2014. 02.009

Lim, C. W., Luan, S., and Lee, S. C. (2014). A prominent role for RCAR3mediated ABA signaling in response to Pseudomonas syringae pv. tomato DC3000 infection in arabidopsis. Plant Cell Physiol. 55, 1691-1703. doi: 10. 1093/pcp/pcu100

Lou, Y.-R., Bor, M., Yan, J., Preuss, A. S., and Jander, G. (2016). Arabidopsis NATA1 acetylates putrescine and decreases defense-related hydrogen peroxide accumulation. Plant Physiol. 171, 1443-1455. doi: 10.1104/pp.16.00446

Macho, A. P., Boutrot, F., Rathjen, J. P., and Zipfel, C. (2012). Aspartate oxidase plays an important role in Arabidopsis stomatal immunity. Plant Physiol. 159, 1845-1856. doi: 10.1104/pp.112.199810

McLachlan, D. H., Kopischke, M., and Robatzek, S. (2014). Gate control: guard cell regulation by microbial stress. New Phytol. 203, 1049-1063. doi: 10.1111/nph. 12916

Melotto, M., Underwood, W., Koczan, J., Nomura, K., and He, S. Y. (2006). Plant stomata function in innate immunity against bacterial invasion. Cell 126, 969-980. doi: 10.1016/j.cell.2006.06.054

Mino, Y., Matsushita, Y., and Sakai, R. (1987). Effect of coronatine on stomatal opening in leaves of broadbean and Italian ryegrass. Jpn. J. Phytopathol. 53, 53-55. doi: 10.3186/jjphytopath.53.53

Misra, H. P., and Fridovich, I. (1972). The role of superoxide anion in the autoxidation of epinephrine and a simple assay for superoxide dismutase. J. Biol. Chem. 247, 3170-3175.

Montillet, J. L., Leonhardt, N., Mondy, S., Tranchimand, S., Rumeau, D., Boudsocq, M., et al. (2013). An abscisic acid-independent oxylipin pathway controls stomatal closure and immune defense in Arabidopsis. PLoS Biol. 11:e1001513. doi: 10.1371/journal.pbio. 1001513

Murata, Y., Pei, Z. M., Mori, I. C., and Schroeder, J. (2001). Abscisic acid activation of plasma membrane $\mathrm{Ca}(2+)$ channels in guard cells requires cytosolic $\mathrm{NAD}(\mathrm{P}) \mathrm{H}$ and is differentially disrupted upstream and downstream of reactive oxygen species production in abi1-1 and abi2-1 protein phosphatase 2C mutants. Plant Cell 13, 2513-2523. doi: 10.1105/tpc.13.11.2513 
Mustilli, A. C., Merlot, S., Vavasseur, A., Fenzi, F., and Giraudat, J. (2002). Arabidopsis OST1 protein kinase mediates the regulation of stomatal aperture by abscisic acid and acts upstream of reactive oxygen species production. Plant Cell 14, 3089-3099. doi: 10.1105/tpc.007906

Ogasawara, Y., Kaya, H., Hiraoka, G., Yumoto, F., Kimura, S., Kadota, Y., et al. (2008). Synergistic activation of the Arabidopsis NADPH oxidase AtrbohD by Ca2+ and phosphorylation. J. Biol. Chem. 283, 8885-8892. doi: 10.1074/jbc. M708106200

Okada, M., Ito, S., Matsubara, A., Iwakura, I., Egoshi, S., and Ueda, M. (2009). Total syntheses of coronatines by exo-selective Diels-Alder reaction and their biological activities on stomatal opening. Org. Biomol. Chem. 7, 3065-3073. doi: 10.1039/b905159g

Panchal, S., Roy, D., Chitrakar, R., Price, L., Breitbach, Z. S., Armstrong, D. W., et al. (2016). Coronatine facilitates Pseudomonas syringae infection of Arabidopsis leaves at night. Front. Plant Sci. 7:880. doi: 10.3389/fpls.2016.00880

Pei, Z. M., Murata, Y., Benning, G., Thomine, S., Klusener, B., Allen, G. J., et al. (2000). Calcium channels activated by hydrogen peroxide mediate abscisic acid signalling in guard cells. Nature 406, 731-734. doi: 10.1038/35021067

Sagi, M., and Fluhr, R. (2006). Production of reactive oxygen species by plant NADPH oxidases. Plant Physiol. 141, 336-340. doi: 10.1104/pp.106.078089

Singh, P., Chien, C. C., Mishra, S., Tsai, C. H., and Zimmerli, L. (2013). The Arabidopsis LECTIN RECEPTOR KINASE-VI.2 is a functional protein kinase and is dispensable for basal resistance to Botrytis cinerea. Plant Signal. Behav. 8: e22611. doi: 10.4161/psb.22611

Singh, P., Kuo, Y. C., Mishra, S., Tsai, C. H., Chien, C. C., Chen, C. W., et al. (2012). The lectin receptor kinase-VI.2 is required for priming and positively regulates Arabidopsis pattern-triggered immunity. Plant Cell 24, 1256-1270. doi: 10.1105/tpc.112.095778

Sirichandra, C., Gu, D., Hu, H. C., Davanture, M., Lee, S., Djaoui, M., et al. (2009). Phosphorylation of the Arabidopsis AtrbohF NADPH oxidase by OST1 protein kinase. FEBS Lett. 583, 2982-2986. doi: 10.1016/j.febslet.2009.08.033

Suhita, D., Raghavendra, A. S., Kwak, J. M., and Vavasseur, A. (2004). Cytoplasmic alkalization precedes reactive oxygen species production during methyl jasmonate- and abscisic acid-induced stomatal closure. Plant Physiol. 134, 1536-1545. doi: 10.1104/pp.103.032250

Thor, K., and Peiter, E. (2014). Cytosolic calcium signals elicited by the pathogen associated molecular pattern flg22 in stomatal guard cells are of an oscillatory nature. New Phytol. 204, 873-881. doi: 10.1111/nph.13064

Torres, M. A., Dangl, J. L., and Jones, J. D. (2002). Arabidopsis gp91phox homologues AtrbohD and AtrbohF are required for accumulation of reactive oxygen intermediates in the plant defense response. Proc. Natl. Acad. Sci. U.S.A. 99, 517-522. doi: 10.1073/pnas.012452499

Veronese, P., Nakagami, H., Bluhm, B., Abuqamar, S., Chen, X., Salmeron, J., et al. (2006). The membrane-anchored BOTRYTIS-INDUCED KINASE1 plays distinct roles in Arabidopsis resistance to necrotrophic and biotrophic pathogens. Plant Cell 18, 257-273. doi: 10.1105/tpc.105. 035576
Xin, X. F., and He, S. Y. (2013). Pseudomonas syringae pv. tomato DC3000: a model pathogen for probing disease susceptibility and hormone signaling in plants. Annu. Rev. Phytopathol. 51, 473-498. doi: 10.1146/annurev-phyto-082712102321

Yan, J., Zhang, C., Gu, M., Bai, Z., Zhang, W., Qi, T., et al. (2009). The Arabidopsis CORONATINE INSENSITIVE1 protein is a jasmonate receptor. Plant Cell 21, 2220-2236. doi: 10.1105/tpc.109.065730

Yin, Y., Adachi, Y., Ye, W., Hayashi, M., Nakamura, Y., Kinoshita, T., et al. (2013). Difference in abscisic acid perception mechanisms between closure induction and opening inhibition of stomata. Plant Physiol. 163, 600-610. doi: 10.1104/ pp.113.223826

Zeng, W., and He, S. Y. (2010). A prominent role of the flagellin receptor FLAGELLIN-SENSING2 in mediating stomatal response to Pseudomonas syringae pv tomato DC3000 in Arabidopsis. Plant Physiol. 153, 1188-1198. doi: $10.1104 /$ pp.110.157016

Zhang, M., Li, Q., Liu, T., Liu, L., Shen, D., Zhu, Y., et al. (2015). Two cytoplasmic effectors of Phytophthora sojae regulate plant cell death via interactions with plant catalases. Plant Physiol. 167, 164-175. doi: 10.1104/pp.114.252437

Zhang, W., He, S. Y., and Assmann, S. M. (2008). The plant innate immunity response in stomatal guard cells invokes G-protein-dependent ion channel regulation. Plant J. 56, 984-996. doi: 10.1111/j.1365-313X.2008.03657.x

Zhang, Y., and Du, G. (2009). Phosphatidic acid signaling regulation of Ras superfamily of small guanosine triphosphatases. Biochim. Biophys. Acta 1791, 850-855. doi: 10.1016/j.bbalip.2009.05.013

Zhao, Z., Zhang, W., Stanley, B. A., and Assmann, S. M. (2008). Functional proteomics of Arabidopsis thaliana guard cells uncovers new stomatal signaling pathways. Plant Cell 20, 3210-3226. doi: 10.1105/tpc.108.063263

Zheng, X. Y., Spivey, N. W., Zeng, W., Liu, P. P., Fu, Z. Q., Klessig, D. F., et al. (2012). Coronatine promotes Pseudomonas syringae virulence in plants by activating a signaling cascade that inhibits salicylic acid accumulation. Cell Host Microbe 11, 587-596. doi: 10.1016/j.chom.2012.04.014

Zhou, Z., Wu, Y., Yang, Y., Du, M., Zhang, X., Guo, Y., et al. (2015). An Arabidopsis plasma membrane proton ATPase modulates JA signaling and is exploited by the Pseudomonas syringae effector protein AvrB for stomatal invasion. Plant Cell 27, 2032-2041. doi: 10.1105/tpc. 15.00466

Conflict of Interest Statement: The authors declare that the research was conducted in the absence of any commercial or financial relationships that could be construed as a potential conflict of interest.

Copyright (c) 2016 Toum, Torres, Gallego, Benavídes, Vojnov and Gudesblat. This is an open-access article distributed under the terms of the Creative Commons Attribution License (CC BY). The use, distribution or reproduction in other forums is permitted, provided the original author(s) or licensor are credited and that the original publication in this journal is cited, in accordance with accepted academic practice. No use, distribution or reproduction is permitted which does not comply with these terms. 